\title{
A SURROGATE APPROACH TO STUDYING THE CHEMICAL REACTIVITY OF BURROW MUCOUS LININGS IN MARINE SEDIMENTS
}

\author{
DANIEL A. PETRASH,${ }^{1 *}$ STEFAN V. LALONDE, ${ }^{2}$ MURRAY K. GINGRAS,${ }^{1}$ and KURT O. KONHAUSER ${ }^{1}$ \\ ${ }^{1}$ Department of Earth and Atmospheric Sciences, 1-26 Earth Science Building, University of Alberta, Edmonton, Alberta, T6G 2E3, Canada, petrash@ualberta.ca, \\ mgingras@ualberta.ca, kurtk@ualberta.ca; 2Institut Universitaire Européen de la Mer IUEM Technopôle Brest-Iroise, rue Dumont d’Urville, Plouzaném, 29280, France, \\ stefan.lalonde@univ-brest.fr
}

\begin{abstract}
Many infaunal marine invertebrates produce mucous excretions, composed primarily of the glycoprotein mucin, that play important roles in burrow stabilization. As with other biopolymers, the ionization of mucin provides highly reactive organic ligands that enable the sorption of metal cations from seawater. Owing to the difficulties in its isolation, however, the specific role of mucin in the adsorptive properties of animal secretions in marine environments is poorly understood. Here we apply a surface complexation approach to model proton and $\mathrm{Cd}$ adsorption behavior of partially purified Type III porcine gastric mucin (PGM), a commercially available analog to natural infaunal mucus. FTIR, proton and cadmium adsorption experiments indicate that Type III PGM mimics the acid-base and metal complexation behavior of natural mucous gels excreted by terebellid polychaete worms. At marine $\mathrm{pH}$, nearly two-thirds of the total ligands in mucin-type glycoproteins are deprotonated and thus available to participate in metal cation adsorption reactions. Importantly, the concentration of available organic ligands in mucin exceeds (by up to 5 times) that of a variety of other metal-reactive organic compounds comprising the organic fraction of marine sediments. A substantial fraction of the dissolved organic matter in the bioturbated zone of marine sediments occurs in the form of mucin-associated glycoproteins; the availability of such organic materials may strongly influence the distribution of cations at the burrow margin.
\end{abstract}

\section{INTRODUCTION}

A large fraction - estimates range between one-third to one-half - of shallow-marine sediments are affected by burrowing activity (e.g., Aller and Aller, 1986; Kostka et al., 2002; Furukawa, 2005). At any given time the density of burrows present may range from less than a few hundred per $\mathrm{m}^{2}$ made by such large animals as lobsters, crabs, and shrimp (e.g., Webb and Eyre, 2004), to as high as several thousand individuals per $\mathrm{m}^{-2}$ in sediments inhabited by such smaller animals as marine annelids (e.g., Bell et al., 1993) and arthropods (e.g., amphipods; Pearson and Gingras, 2006). Burrowing activities increase the area of the sediment-water interface by as much as ten-fold: the amount of area increase depends on the burrow architecture and the population density (Koretsky et al., 2002).

Burrows in marine environments primarily serve as refuges from predation or result from the feeding activities of infaunal animals (Kristensen and Kostka, 2005; Seilacher, 2007). These functions are facilitated by the animal's continual secretion of mucus, an organic polymer that occurs as either a gel layer coating the sediment grains near and at the burrow wall or as a colloidal suspension within the sediment pore water (Bonar, 1972; Storch, 1988; Har-El and Tanzer, 1993; Davis and Viney, 1998). Fecal strings and pellets may also contain mucus; these can be concentrated at the sediment-water interface or as burrow infilling.

* Corresponding author.

Copyright $\odot$ 2011, SEPM (Society for Sedimentary Geology)
Burrowing animals play an important sedimentological role in that they physically disrupt the surface layers (bioturbation) through mixing and reworking of fresh sediment with older reduced sediment and sorting particles during feeding and burrow construction. Animal activities may result in localized grazing and disintegration of organic remains. The ingestion of refractory organic carbon leads to the excretion of more labile organic material, which stimulates the colonization of the tube by prokaryotic communities (Kristensen and Kostka, 2005). Meanwhile, renewal of burrow water via ventilation enhances the exchange of solutes and gases between the sediment and overlying waters (Ziebis et al., 1996). This leads to increased transport of reduced metabolic by-products (e.g., $\mathrm{NH}_{4}^{+}, \mathrm{Fe}^{2+}, \mathrm{HS}^{-}$) upward and away from the burrows to the sediment-water interface while also bringing dissolved oxidants (e.g., $\mathrm{NO}_{3}^{-}, \mathrm{O}_{2}$ ) downward to deeper anoxic sediment (e.g., Kristensen et al., 1985; Kristensen and Kostka, 2005).

The processes described here foster a number of microbially driven redox reactions that not only influence the solid-phase and pore-water properties of sediment, but the overall cycling of major nutrients $(\mathrm{C}, \mathrm{N}$, $\mathrm{Fe}, \mathrm{S}$, and P) in the costal marine environment (Kristensen, 2001; Kostka et al., 2002). With steep geochemical gradients and narrow redox zonations separating the inside of the burrow from the surrounding sediment matrix, the bioturbated sediment-water interface serves as a locus for both ion adsorption and mineralization reactions (Over, 1990; Aller and Aller, 1998; Petersen et al., 1998; Aller, 2001). Indeed, a number of studies have documented trace metal enrichment (e.g., Fe, Mn, Zn, P) and mineral impregnation (e.g., metal oxides and sulphides) in polychaete burrow walls (i.e., Aller and Yingst, 1978; Kristensen, 1984).

Despite the recognized importance of burrow linings in mediating the chemical composition of shallow-marine sediments (Aller, 1982, 1983, 1988; Petersen et al., 1998), these mechanisms of elemental concentration and exchange at the burrow margin have not received significant attention. In fact, other than Petersen et al. (1998), who suggested that mucoidal burrow linings play an important role in increasing trace metal concentrations in sediment surrounding burrows, almost no direct research has been conducted.

Most of the rheological, physiochemical, and geochemical properties of mucous linings are due to the mucin-type glycoproteins they contain (Davis and Viney, 1998; Strous and Dekker, 1992; Bansil et al., 1995; Bansil and Turner, 2006). Polyelectrolyte functional groups, comprising the macromolecular structure of mucin, deprotonate under typical $\mathrm{pH}$ conditions of marine pore water systems, conferring a net negative charge to mucous gels that allow them to react with dissolved cations (Aller, 1983; Marriot and Gregory, 1990; Bansil and Turner, 2006). Lalonde et al. (2010) indicated that mucous secretions of marine worms are unusually reactive, possessing a high density (per unit mass) of organic functional groups with the potential to exert control over element partitioning between overlying seawater and bioturbated sediments.

0883-1351/11/0026-0594/\$3.00 
The inherent difficulty in isolating animal mucus from marine sediments, however, represents a major obstacle in understanding its role in the geochemistry of the burrow-sediment interface. In this regard, the identification of a suitable commercial analog in terms of metal-binding properties would facilitate a better understanding of the role of mucin-based gels in the nucleation and selective precipitation of minerals within burrowed sediments (Mitterer, 1971; Over, 1990; Gingras et al., 2004; Kristensen and Kostka, 2005). The advantages of a surrogate approach include easier protocols and increased experiment-design flexibility to model the geochemical effects of burrow linings. In this contribution we demonstrate that the commercially available Type III porcine gastric mucin (PGM) represents a strong candidate to act as such an experimental surrogate as its reactive site identities, available site concentrations, and $\mathrm{Cd}$ adsorption behavior strongly resemble that of mucous secretions secreted by terebellid polychaetes under laboratory conditions (Lalonde et al., 2010).

\section{METHODS}

In earlier studies, FTIR (Fourier Transform Infrared) analysis of mucus produced by marine invertebrates showed similarities to spectra collected from partially purified mammalian mucin glycoproteins (Bavington et al., 2004). Accordingly, for this study we identified the commercially available and well-characterized Type III porcine gastric mucin (PGM) (Sigma-Aldrich Canada, Oakville, Ontario) as a candidate surrogate.

\section{Fourier Transform Infrared (FTIR)}

FTIR spectroscopy was used to determine the bond types and identities of the organic functional groups present in Type III PGM. These spectra were subsequently compared with FTIR spectra of mucus produced under experimental conditions by terebellid polychaetes (Lalonde et al., 2010). For FTIR analysis, a dry sample was placed on a salt plate $(\mathrm{KCl})$ and then examined using a Nic-Plan IR microscope attached to a Nicolet Magna-IR spectrometer 750. Spectra were acquired from 600 to $4,000 \mathrm{~cm}^{-1}$ in absorbance mode and converted to transmittance.

\section{Alkalimetric Titrations}

The process of determining the ligand concentrations by adding a base, with which the ligands react, is called alkalimetric titration. The addition of aliquots of base causes the organic functional groups to deprotonate progressively. Thus, the alkalimetric titration data can be evaluated in terms of excess charge in order to obtain concentrations and acidity constants for proton reactive organic functional groups present in the Type III PGM material. The acidity constant is represented as $\mathrm{pK}_{a}\left(-\log \mathrm{K}_{a}\right)$, which is approximately equivalent to the $\mathrm{pH}$ at which an equal amount $(50 \%)$ of sites are in protonated and deprotonated forms.

For alkalimetric titration, solutions of Type III PGM were prepared gravimetrically to concentrations of approximately 1.0 dry $\mathrm{g} / \mathrm{L}$ in $0.01 \mathrm{M} \mathrm{NaNO}$ and acidified with $2 \mathrm{M}$ of trace metal grade $\mathrm{HNO}_{3}$ to a $\mathrm{pH}$ of $\sim 3.0$. A pH electrode (Orion ROSS ultra) was calibrated using commercial $\mathrm{pH}$ buffers and mounted into flasks containing the titrate solutions along with a magnetic stir bar, titrant dispenser, thermometer, and $\mathrm{Ar}$ gas line. Both the titrate and titrant were stored in closed containers and bubbled for 30 min with Ar gas to expel $\mathrm{CO}_{2}$ from the system prior to, and throughout, titration.

Titrations were conducted from $\mathrm{pH} 3$ to 11 using a PC-Titrate autotitrator (Mandel Scientific, Guelph, Ontario) programmed to deliver aliquots of $0.01 \pm 0.0001 \mathrm{M} \mathrm{NaOH}$ (commercial titrant, Thermo Fisher Scientific, Waltham, Massachusetts) in increments of 10 additions per
$\mathrm{pH}$ unit, with stability criteria of $0.5 \mathrm{mV} / \mathrm{s}$ or less between additions. The suspension was allowed to equilibrate after each base addition prior to the addition of the next aliquot of base. Each titration lasted approximately 1 hour, with sample temperature remaining approximately constant $\left(23 \pm 1{ }^{\circ} \mathrm{C}\right)$ throughout all titrations.

Two approaches can be used to model the deprotonation of organic ligands in mucous gel: (1) a Donnan electrostatic model, which assumes that all ions necessary to balance the adsorption of metal are present within the mucin gel volume; or (2) a non-electrostatic model, which assumes that the ionic strength effect on the mucin gel proton binding reactions is relatively small over the range of 0.01 to $0.5 \mathrm{M}$ and, therefore, is not significantly greater than the experimental and modeling uncertainties.

A non-electrostatic model was chosen as only one ionic strength was explored $(0.01 \mathrm{M})$, and previous studies have demonstrated that electrostatic surface field effects on protonation are minimal for bacterial surfaces (Borrok et al., 2004) and humic and fulvic acids (Truitt and Weber, 1981). Titration data were modeled using leastsquares optimization as implemented in FITEQL 4.0 (Herbelin and Westall, 1999). The FITEQL optimization algorithm iteratively minimizes a variance function, $V_{Y}$, which is the weighted sum of squares of residuals divided by the degrees of freedom between the experimental data and the model; a variance of less than 20 is considered a good fit to the experimental data. Technical details of the FITEQL algorithm can be found in Herbelin and Westall (1999).

The charge balance in each titration step was calculated by the following charge balance equation:

$$
\left[\mathrm{C}_{\mathrm{a}}-\mathrm{C}_{\mathrm{b}}\right]=[-\mathrm{Q}]+\left[\mathrm{H}^{+}\right]-\left[\mathrm{OH}^{-}\right]
$$

where $\left[\mathrm{C}_{\mathrm{a}}-\mathrm{C}_{\mathrm{b}}\right]$ is the concentration of acid added minus the concentration of base added; $\left[\mathrm{H}^{+}\right]$and $\left[\mathrm{OH}^{-}\right]$are the concentrations of proton and hydroxyl ions, respectively, and $[-\mathrm{Q}]$ is the negative charge excess owing to deprotonation of mucin in solution, normalized per gram of material. For titration data modeling, site concentrations and acidity constants (expressed here as $\mathrm{pK}_{a}$, equivalent to $-\log \mathrm{K}_{a}$ ) were iteratively adjusted by FITEQL to fit charge excess vs. $\mathrm{pH}$ data for a predetermined number of discrete sites (1-3).

\section{Cadmium Complexation}

Cadmium adsorption behavior of mucin was examined using a dialysis separation technique that facilitates separation of free $\mathrm{Cd}$ ions from mucin macromolecules and their $\mathrm{Cd}$ complexes by selective diffusion through a semipermeable cellulose membrane $(10 \mathrm{~mm}$ diameter Spectra-Por cellulose membranes, $12-14$ kDa cutoff, ColeParmer Canada Inc., Montreal, Quebec). The dialysis membranes were soaked for $30 \mathrm{~min}$ and washed 3 times with $18.2 \mathrm{M} \Omega$ water in order to remove organic surfactants from the membranes. Solutions of $0.01 \mathrm{M}$ $\mathrm{NaNO}_{3}$ with a concentration of $\sim 5 \mathrm{mg} / \mathrm{L}$ of $\mathrm{Cd}$ (from a $1000 \mathrm{ppm}$ commercial standard solution, Thermo Fisher Scientific, Waltham, Massachusetts) were prepared in triplicate. The dialysis tubes were then filled with $\sim 1.1 \mathrm{~mL}$ of the $\mathrm{Cd}$ solution, previously adjusted to a $\mathrm{pH}$ of 6.0 with metal trace grade $\mathrm{HNO}_{3}$, and sealed with $12 \mathrm{~mm}$ polypropylene clips.

Two mucin to Cd ratios were experimentally tested, 1:1 and 3:1, with experiments conducted in triplicate to average mucin concentrations of 1.48 and $4.15 \mathrm{~g}$ mucin/L, respectively. The $\mathrm{Cd}$ solutions were mixed with PGM by magnetic stirring until achieving a gel consistency ( $\sim 30 \mathrm{~min}$.). Forty $\mathrm{ml}$ aliquots of the mucin-Cd solution were added into eight $50 \mathrm{ml}$ polypropylene centrifuge tubes. The $\mathrm{pH}$ in each centrifuge tube was adjusted to between 3 and 10 in increments of one $\mathrm{pH}$ unit, using concentrated $\mathrm{HNO}_{3}$ or $\mathrm{NaOH}$. This was followed by immersion of the diffusate (mucin-free $\mathrm{Cd}$ solution, contained in the dialysis tubes), within the centrifuge tubes 


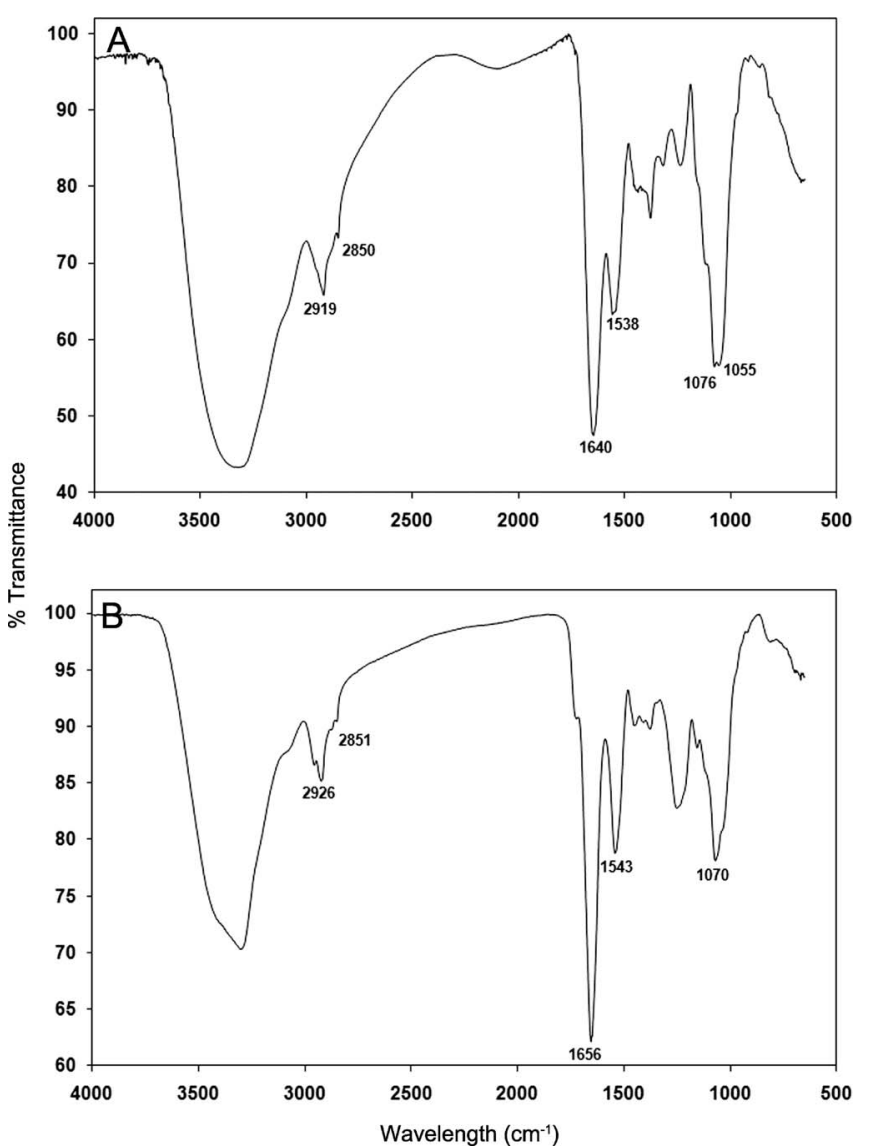

FIGURE 1-FTIR spectra of (A) Type III PGM (this study), and (B) terebellid worm mucous secretion (Lalonde et al., 2010).

containing the mucin-Cd solution (retentate). $\mathrm{pH}$ values of the retentate were recorded before and after the equilibration period, with the final $\mathrm{pH}$ value assumed to represent equilibrium between the diffusate and retentate.

Cadmium within the dialysis tube remains largely in the form of $\mathrm{Cd}^{2+}$ over the acidic to circumneutral $\mathrm{pH}$ range. As adsorption of free $\mathrm{Cd}$ by mucin-reactive sites occurs, $\mathrm{Cd}^{2+}$ in solution crosses the semipermeable membrane until equilibrium is reached. To achieve $\mathrm{Cd}^{2+}$ equilibrium between the diffusate and the retentate solutions, the experiments were placed in an incubator at $25{ }^{\circ} \mathrm{C}$ while undergoing constant agitation (40 rpm) for a period of 24 hours (Truitt and Weber, 1981).

In our adsorption experiments, $\mathrm{Cd}$ cations adsorbed to mucin reactive sites are retained entirely outside the cellulose membrane, as the membrane cutoff, 1.2 to $1.4 \times 10^{4} \mathrm{Da}$, is two orders of magnitude lower than the average molecular molar mass $\left(1.6 \times 10^{6} \mathrm{Da}\right)$ of the commercial Type III PGM (Davis and Viney, 1998). Once equilibrium was reached, the total concentration of $\mathrm{Cd}^{2+}$ inside the dialysis tubes is considered to be equal to free $\mathrm{Cd}^{2+}$ in the system, and the contents of the dialysis tubes were collected, immediately diluted with 18.2 $\mathrm{M} \Omega$ water, and acidified with concentrated trace-metal $\mathrm{HNO}_{3}$.

Equilibration with respect to free $\mathrm{Cd}^{2+}$ is assumed to occur across the membrane such that $\mathrm{Cd}$ concentrations in the mucin-free compartment reflect equilibrium between mucin-bound and free $\mathrm{Cd}^{2+}$. $\mathrm{Cd}$ concentrations were analyzed by atomic absorption spectroscopy (Perkin Elmer 3000) to determine the proportion of free $\mathrm{Cd}^{2+}$ at the various experiment $\mathrm{pH}$ values. $\mathrm{Cd}$ activities were determined from concentration data using coefficients calculated by the Davies equation for the following reactions (for ligands $\mathrm{L}_{1}$ to $\mathrm{L}_{3}$ ):
TABLE 1-FTIR peak absorption frequencies. Tentative peak assignments of Type III PGM and comparison with terebellid mucus.

\begin{tabular}{|c|c|c|}
\hline \multicolumn{2}{|c|}{ Peak absorption frequency $\left(\mathrm{cm}^{-1}\right)$} & \multirow[b]{2}{*}{ Peak assignment } \\
\hline PGM & Terebellid mucus & \\
\hline $1055-1076$ & 1070 & $\begin{array}{l}\text { C-O stretching of complex sugars, } \mathrm{S}=\mathrm{O} \\
\text { stretching }\end{array}$ \\
\hline- & 1180 & $\mathrm{~S}=\mathrm{O}$ stretching \\
\hline 1237 & 1230 & Acetyl C-O-C \\
\hline 1451 & 1448 & $\mathrm{CH}_{2}$ scissoring \\
\hline 1538 & 1543 & N-H bending (amide II) \\
\hline 1640 & 1656 & $\mathrm{~N}$-acetyl $\mathrm{C}=\mathrm{O}$ stretching (amide I) \\
\hline 2850,2919 & 2851, 2926 & C-H stretching \\
\hline
\end{tabular}

Best-fit equilibrium constants for $\mathrm{Cd}^{2+}$-mucin complexes were found by least-squares optimization as implemented in the computer software FITEQL 4.0. Cd-ligand stability constants are defined as:

$$
\mathrm{K}_{\mathrm{CdL}}=\left[\mathrm{R}-\mathrm{L}_{\mathrm{n}}(\mathrm{Cd})^{+}\right] \cdot\left(\left[\mathrm{R}-\mathrm{L}_{\mathrm{n}}{ }^{-}\right] a_{\mathrm{Cd}(\mathrm{II})}\right)^{-1} ;
$$

where $\mathrm{R}-\mathrm{L}_{\mathrm{n}}(\mathrm{Cd})^{+}$is the Cd-organic complex, $\left[\mathrm{R}-\mathrm{L}_{\mathrm{n}}{ }^{-}\right]$is the concentration of ligands and $a_{\mathrm{Cd}(\mathrm{II})}$ is the activity of $\mathrm{Cd}$ in solution. The equilibrium constant, $\mathrm{K}_{\mathrm{CdL}}$, is reported as $\log \mathrm{K}_{\mathrm{CdL}}$ for triplicate experiments.

\section{RESULTS}

\section{FTIR Spectra}

Figure 1A shows that FTIR spectra of porcine gastric mucin are broadly consistent with spectra previously reported for terebellid polychaete mucous secretions (Fig. 1B; Lalonde et al., 2010), as well as other natural mucin-type glycoproteins in general (Bavington et al., 2004, fig. 4). On the basis of the known mucin compositional constraints (Davis and Viney, 1998), the strong absorption peaks at $1,050-1,240 \mathrm{~cm}^{-1}$ are tentatively assigned to $\mathrm{C}-\mathrm{O}$ stretching and $\mathrm{S}-\mathrm{O}$ stretching; bands representing $\mathrm{N}-\mathrm{H}$ bending (amide II) and $\mathrm{N}-\mathrm{C} \mathrm{O}$ stretching (amide I) are present at $1538 \mathrm{~cm}^{-1}$, and $1640-\mathrm{cm}^{-1}$, respectively (Table 1). These bands are likely indicative of bonds associated with glycosaminoglycans. Various $\mathrm{C}-\mathrm{H}$ stretching modes are present at 2,850 and 2,919 $\mathrm{cm}^{-1}$ (Table 1, Fig. 1).

\section{Potentiometric Titrations}

Figure 2A shows all titration data plotted in terms of millimoles of deprotonated sites (or charge excess) per unit of mucin dry mass. The slope at any given point can be interpreted as the instantaneous buffering capacity at that $\mathrm{pH}$; Type III PGM displayed a significant buffering capacity over the entire $\mathrm{pH}$ range of this study (4-10). The excess charge data was best fit by a three-site model, with apparent $\mathrm{pK}_{a}$ $\left(-\log \mathrm{K}_{a}\right)$ values of $4.82 \pm 0.03,7.08 \pm 0.12$, and $9.30 \pm 0.01$.

The model site distributions are shown at Figure 2B, with functional group acidity constants and concentrations of functional group presented in Table 2. Based on compositional data, FTIR spectra, and analogy in acidity constants with respect to known compounds, the three sites most likely correspond to carboxyl, phosphoryl, and thiol and/or amine organic functional groups, respectively.

Over the experimental $\mathrm{pH}$ range, the total functional group concentrations available for metal binding are $17.27 \pm 1.05 \mathrm{mmol} \cdot \mathrm{g}^{-1}$ (dry) (Table 2). The total proton reactivity of Type III PGM reported here is elevated relative to other naturally occurring biomass, i.e., fulvic substances (averaging $7.74 \mathrm{mmol} / \mathrm{g}$ ), but is comparable to terebellid mucous secretions $\left(11.26 \pm 1.79 \mathrm{mmol} \cdot \mathrm{g}^{-1}\right)$ (Lalonde et al., 2010). 

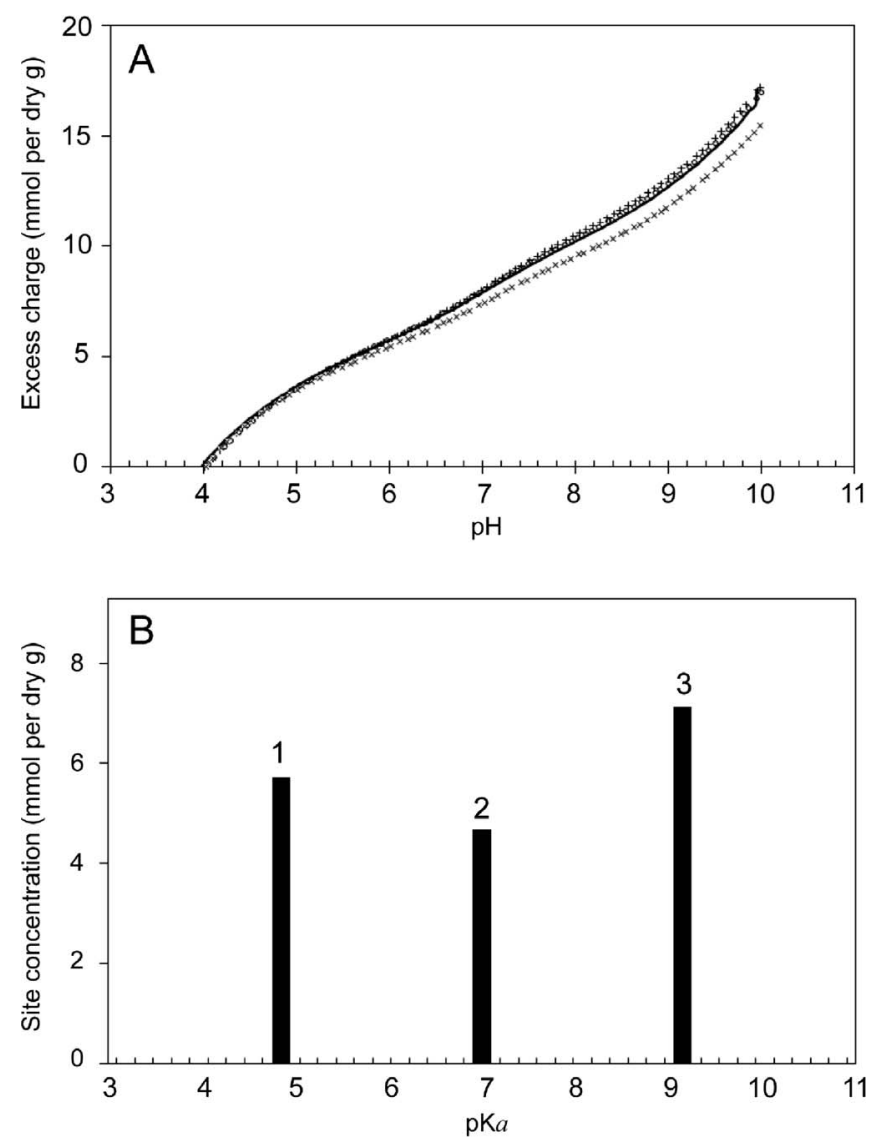

FIGURE 2-Best-fit non-electrostatic proton adsorption and discrete ligand models of titration data. (A) Potentiometric titration data (points) for three titrations of Type III PGM in $0.1 \mathrm{M} \mathrm{NaNO}_{3}$. Also displayed is a solid line representing the best-fit 3-site surface protonation model. (B) Average best-fit discrete site model obtained by leastsquares optimization of titration data as implemented in FITEQL 4.0 (Westall, 1982). The model represents the set of functional groups, in terms of concentration (y-axis) and acidity constant (x-axis), that best describes the charge excess data.

\section{Cd Adsorption}

$\mathrm{Cd}$ is often used as a model divalent metal for the following reasons: (1) Cd remains soluble over the $\mathrm{pH}$ range of most marine environments; (2) unlike $\mathrm{Ca}$ and $\mathrm{Mg}$, its use in laboratory settings is not complicated by carbonate complexation and precipitation; (3) to facilitate comparison with other adsorption studies involving fulvic and humic acids or bacteria that use $\mathrm{Cd}$ as a model divalent metal; and (4) for its relevance to nearshore marine and estuarine waters, where $\mathrm{Cd}$ concentrations may be elevated (i.e., Petersen et al., 1998).

For sites 1 and 2, Cd stability constants were modeled using the average Type III PGM site concentrations and their acidity constants (Table 2), combined with experimental Cd adsorption data. In our experiments, simple monodentate surface complexation of free $\mathrm{Cd}^{2+}$ by deprotonated surface sites adequately described $\mathrm{Cd}^{2+}$ adsorption behavior. The best fit was achieved when two sites participated in $\mathrm{Cd}$ adsorption (Figs. 3A, B). The Cd-ligand stability constants (as $-\log$ $\mathrm{K}_{\mathrm{Cd}}$ values) determined for these ligands, likely composed of carboxyl and phosphoryl moieties, are $2.54 \pm 0.11$ and $3.89 \pm 0.30$, comparable to those previously reported for corresponding sites in the terebellid worm mucous secretions $\left(-\log \mathrm{K}_{\mathrm{Cd}}\right.$ values of 2.19 and 3.86; Lalonde et al., 2010).

In experiments with a high mucin to metal ratio (mucin concentration: $\sim 4.2 \mathrm{~g} / \mathrm{L}$; Fig. 3A), nearly complete removal of Cd from solution occurs at a $\mathrm{pH}$ above 6 , and a plateau in the adsorption edge is observed. As inferred from the $\mathrm{pH}$-sorption edges of our low mucin to
TABLE 2-Parameters obtained from best-fit non-electrostatic proton adsorption models of titration data (expressed here as $\mathrm{pK}_{a}$ ), and best-fit Cd-ligand stability constants ( $\log \mathrm{K}$ values) for sites 1 and 2 . Precipitation of Cd-hydroxides in the alkaline $\mathrm{pH}$ range make it difficult to determine the Cd-complexing capacity of site 3 .

\begin{tabular}{lccc}
\hline \hline Site & Average $\mathrm{pK}_{a}$ & $\begin{array}{c}\text { Average C } \\
(\mathrm{mmol} / \mathrm{dry} g)\end{array}$ & $\log \mathrm{K}_{\mathrm{CdL}}$ \\
\hline $\mathbf{1}$ & $4.82 \pm 0.02$ & $5.73 \pm 0.23$ & $2.54 \pm 0.11$ \\
$\mathbf{2}$ & $7.08 \pm 0.12$ & $4.67 \pm 0.40$ & $3.89 \pm 0.30$ \\
$\mathbf{3}$ & $9.30 \pm 0.01$ & $6.89 \pm 0.43$ & - \\
\hline
\end{tabular}

metal experiments (Fig. 3B) at $\mathrm{pH} \sim 6$ site 1 becomes saturated; with increasing $\mathrm{pH}$, site 2 becomes progressively deprotonated and any $\mathrm{Cd}^{2+}$ remaining in solution can be complexed by deprotonated ligands (Fig. 3C).

\section{DISCUSSION}

While the composition of mucin appears relatively conserved among different animals, and secretions produced by dissimilar species share many common features (Bavington et al., 2004; Stabili et al., 2009), there may be heterogeneities related to specialized roles that mucus performs in marine invertebrates (Storch, 1988; Mastrodonato et al., 2006). The striking similarities in the spectral response of Type III PGM and terebellid mucus (Table 1, Fig. 1) arise from the common organic functional groups comprising mucin-type glycoproteins, a deeply branching and compositionally conserved constituent of animal epithelial secretions (Bavington et al., 2004; Lang et al., 2007). In terms of available functional groups amenable for metal binding, the similarity in the FTIR spectra of both Type III PGM and terebellid worm secretions indicate that the former is an appropriate experimental surrogate for examining the sorptive properties of marine invertebrate mucin glycoproteins.

Approximately $80 \%$ of mucin's molecular mass is composed of carbohydrates, primarily $\mathrm{N}$-acetylgalactosamine, $\mathrm{N}$-acetylglucosamine, galactose, sialic acid ( $N$-acetylneuraminic acid), with trace amounts of mannose and sulfate (Bansil and Turner, 2006). The oligosaccharides are arranged in O-linked chains containing 5 to 30 monomeric units and are attached to the protein core by O-glycosidic bonds to the hydroxyl side chains of amino acids serine and threonine, which are exposed by the protein core (Davis and Viney, 1998; Bansil and Turner, 2006). The protein core, making up approximately $20 \%$ of the average molecular mass, possesses two distinct regions (Bansil and Turner, 2006). One is a central glycosylated region composed of repeating units rich (up to $60 \%$ ) in the amino acids serine, threonine, and proline. At the amino and carboxyl terminals, regions are more representative of globular proteins, and are high $(>10 \%)$ in cysteine; it is this region that is believed to confer viscoelasticity of mucin oligomers by extensive disulfide bonding between cysteines (Gum et al., 1992).

The extended fibrous structure of mucin, approximately $400 \mathrm{~nm}$ in length at pH 5-7 (Hong et al., 2005), may provide proton access to sites that would otherwise be inaccessible in other, more condensed, natural organic macromolecules. Importantly, mucin glycoproteins appear to have a buffering capacity that is evenly distributed over the $\mathrm{pH}$ range of most marine pore water systems, and at seawater $\mathrm{pH}$, nearly two-thirds of its total ligands will be deprotonated and available to participate in metal cation adsorption reactions. Our results on Type III PGM demonstrate that at the typical $\mathrm{pH}$ conditions of marine bioturbated sediments, carboxyl and phosphoryl ligands comprising mucin glycoproteins in burrow mucus have the potential to bind a significant fraction of dissolved metals in solution at the burrow margin. Given that thiol functional groups are inherent to the cysteine-rich domains of mucin substances and are present in Type III PGM (as indicated by previous compositional constraints, FTIR, and potentiometric titration), it is likely that thiol and amino groups, represented by site 3 

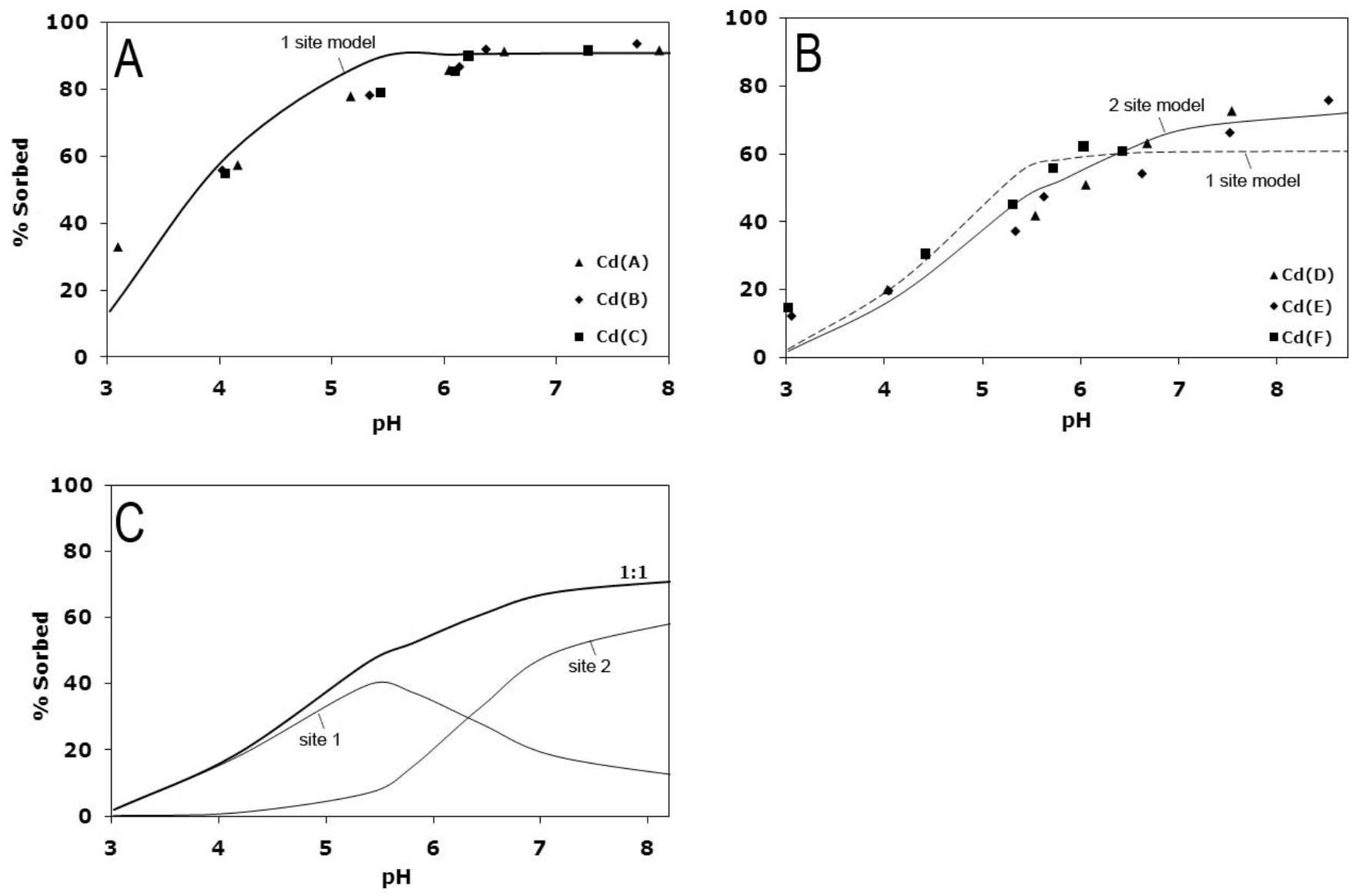

FIGURE 3-Cd adsorption in $5 \mathrm{ppm} \mathrm{Cd}$-mucin solutions. A decrease in the mucin/metal ratio leads to a depressed adsorption edge, and Cd sorption to more than one functional group is required to fit the data. (A) With $4.17 \mathrm{~g} / \mathrm{L}$ mucin (Experiments $\mathrm{A}, \mathrm{B}$, and C). (B) With $1.48 \mathrm{~g} / \mathrm{L}$ mucin (Experiments D, E, and F). (C) In experiments conducted with low mucin concentrations, the sorption behavior can be explained by $\mathrm{Cd}$ complexation into reactive sites 1 and 2 .

(Figure 2) will confer an unusually high affinity for $\mathrm{Cd}$ and other divalent metals in the alkaline $\mathrm{pH}$ range, as is the case for terebellid mucus (Lalonde et al., 2010).

\section{PERSPECTIVES}

As demonstrated in this study, the polyanionic nature of the mucin glycoproteins in mucous secretions of burrowing animals is responsible for the speciation and mobility of dissolved metals in contact with burrow wall linings (e.g., Lalonde et al., 2010). In turn, this is expected to influence mineral precipitation and metal cycling in bioturbated environments (Over, 1988, 1990; Petersen et al., 1998; Zorn et al., 2007). In fact, the presence and reactivity of mucin may, in part, explain complex burrow-selective metal enrichment observed in other carbonate strata (e.g., Red River Formation, Palliser Formation, Beales, 1953; Zenger, 1996) and in siliciclastic rocks (e.g., Birket Qarun Formation, Abdel-Fattah et al., 2010). Early cementation of sediment under the influence of carboxylated organic matter, such as mucin, however, is often overlooked in favor of deeper-seated diagenetic processes. This general oversight suggests that geologists working in the deeper rock record may substantially underestimate the influence of bioproductivity - on and within seafloor sediments - on early diagenetic processes. Understanding the mechanisms and impacts of mucin-facilitated metal sorption and authigenic mineral precipitation would help build better models of important diagenetic features including mineral-phase distribution, permeability, and porosity, which are necessarily pursued in the oil industry.

A direct empirical study of the metal reactivity of mucin from natural bioturbated environments has been hindered by the inherent complexity of these systems and the lack of suitable methods for their separation from other organic and inorganic compounds that make up the organic-rich matrices of bioturbated sediment. Thus, the biogeochemical reactions controlling mineral authigenesis in sediments and the specific role of animal mucus remains largely unexplored. Understanding the intricacies of metal binding by mucin should lead to new opportunities to experimentally examine infaunal animal controls on mineral nucleation.

With respect to carbonate minerals, such control is likely strong. In the rock record, the activity of burrowing animals has been linked with selective dolomitization in the Upper Ordovician Tyndall limestone, where burrows form the locus for dolomite mineralization (Gingras et al., 2004). A threefold mechanism by which mucus would influence biomineralization in bioturbated sediments was envisioned by Gingras et al. (2004) as follows: (1) Adsorption of dissolved metal cations (e.g., $\mathrm{Ca}^{2+}, \mathrm{Mg}^{2+}, \mathrm{Fe}^{2+}, \mathrm{Fe}^{3+}$ ) by mucin would create a gel-like matrix that is potentially oversaturated with some authigenic mineral phases (e.g., metal carbonates and hydroxides). (2) Heterotrophic bacteria that colonize burrow linings partially degrade the glycoprotein-rich mucin substrate, establishing $\mathrm{pH}$ gradients around and across the burrow wall and surrounding sediments (i.e., Zhu et al., 2006). (3) Heterotrophic metabolism of mucus-coated, fine-grained sediment particles would further result in metal release.

As intense chemical mass transfer occurs in the wall microenvironment (Furukawa, 2001), reactants within the wall microenvironments nucleate and would potentially lead to dolomite precipitation in the proximities of burrow walls. Modern experiments similarly indicate that metal complexation by such carboxylated biomaterials as mucin plays a strong role in controlling mineral nucleation. In the case of 
amorphous calcium carbonate precipitation, carboxylated biomolecules exert strong control over solid phase $\mathrm{Mg} / \mathrm{Ca}$ ratios, which in turn can be related to the sequence of calcium and magnesium affinity of the carboxylated biomolecules (Aizenberg et al., 1996; Han and Aizenberg, 2003; Wang et al., 2009). Progress in applying such knowledge to the natural bioturbated sediment-water interface, however, is hampered by difficulties in isolating natural animal mucus. In this regard, the use of PGM as an experimental surrogate should facilitate future research aimed at better understanding how naturally occurring animal mucus exerts control over the incorporation of metals into carbonate phases in bioturbated marine sedimentary systems.

\section{CONCLUSIONS}

This work provides empirical evidence for the usefulness of the commercially available Type III porcine gastric mucin (PGM) as an analog to modeling the impact of benthic infaunal mucus on the chemical composition of shallow-marine sediments. The organic functional groups comprising PGM have acidity constants $\left(\mathrm{pK}_{a}\right)$ at $4.8,7.0$, and 9.3 , and display a total proton adsorptive capacity of 17.2 $\pm 1.0 \mathrm{mmol} \cdot \mathrm{g}^{-1}$; two-thirds of which is potentially available for metal binding in the circumneutral to alkaline $\mathrm{pH}$ range. In this regard, the compositional and intrinsic thermodynamic parameters describing the Cd-adsorption behavior of PGM are comparable with those of terebellid worm mucous secretions. Understanding the reactivity and sorptive properties of mucin-type glycoproteins is critical in evaluating the role that burrowing animals may play in the incorporation of metals into early diagenetic shallow-marine carbonate cements.

\section{ACKNOWLEDGMENTS}

We thank Ariel Anbar, an anonymous reviewer, and Coeditor Stephen T. Hasiotis for their insightful comments and suggestions. KOK and MKG thank the Natural Sciences and Engineering Research Council of Canada (NSERC) for ongoing support.

\section{REFERENCES}

Abdel-Fattah, Z.A., Gingras, M.K., and Pemberton, S.G., 2010, Significance of hypoburrow nodule formation associated with large biogenic sedimentary structures in open-marine bay siliciclastics of the Upper Eocene Birket Qarun Formation, Wadi El-Hitan, Fayum, Egypt: Sedimentary Geology, doi: 10.1016/ j.sedgeo.2010.11.001.

Aizenberg, J., Lambert, G., Addadi, L., and Weiner, S., 1996, Stabilization of amorphous calcium carbonate by specialized macromolecules in biological and synthetic precipitates: Advanced Materials, v. 8, p. 222-226.

Aller, R.C., 1982, The effects of macrobenthos on chemical properties of marine sediment and overlying water, in McCall, M.J.S., and Tevez, P.L., eds., Animal-Sediment Relations: Plenum Publishing Company, New York, p. 53-102.

Aller, R.C., 1983, The importance of the diffusive permeability of animal burrow linings in determining marine sediment chemistry: Journal of Marine Research, v. 41 , p. $299-322$.

Aller, R. C., 1988, Benthic fauna and biogeochemical processes in marine sediments: The role of burrow structures, in Blackburn T H., and Sørensen J., eds., Nitrogen Cycling in Coastal Marine Environments: Wiley, Chichester, p. 301-339.

Aller, R.C., 2001, Transport and reactions in the bioirrigated zone, in Boudreau, B.P., and Jørgensen, B.B., eds., The Benthic Boundary Layer: Transport Processes and Biogeochemistry: Oxford University Press, Oxford, UK, 2001, p. $269-301$.

Aller, J. Y., and Aller, R.C., 1986, Evidence for localized enhancement of biological activity associated with tube and burrow structures in deep sea sediments at the Hebble Site, western North Atlantic: Deep Sea Research, v. 33, p. $755-790$.

Aller, R.C., and Aller, J.Y., 1998, The effect of biogenic irrigation intensity and solute exchange on diagenetic reaction rates in marine sediments: Journal of Marine Research, v. 56, p. 905-936.

Aller, R.C., and Yingst, J.Y., 1978, Biogeochemistry of tube-dwellings: A study of the sedentary polychaete Amphitrite ornata (Leidy): Journal of Marine Research, v. 36 , p. 201-254.
Bansil, R., Stanley, E., and Lamont, J., 1995, Mucin biophysics: Annual Reviews in Physiology, v. 57, p. 635-657.

BANSIL, R., and TuRNER, B.S., 2006, Mucin structure, aggregation, physiological functions and biomedical applications: Current Opinion in Colloid \& Interface Science, v. 11, p. 164-170.

Bavington, C.D., Lever, R., Mulloy, B., Grundy, M.M., Page, C.P., Richardson, N.V., and MckenzIE, J.D., 2004, Anti-adhesive glycoproteins in echinoderm mucus secretions: Comparative Biochemistry and Physiology Part B: Biochemistry and Molecular Biology, v. 139, p. 607-617.

Beales, F.W., 1953, Dolomitic mottling in Palliser (Devonian) limestone, Banff and Jasper National Parks, Alberta: Bulletin of the American Association of Petroleum Geologists, v. 37, p. 2281-2293.

Bell, S.S., Clements, L.A.J., and Kurdziel, J., 1993, Production in natural and restored seagrasses: A case study of a macrobenthic polychaete: Ecological Applications, v. 3, p. 610-621.

BonAR, D.B., 1972, Feeding and tube construction in Chone mollis (Bush) (Polychaeta, Sabellidae): Journal of Experimental Marine Biology and Ecology, v. 9, p. 1-18.

Borrok, D., Fein, J.B., and KulPa, C.F., 2004, Proton and Cd sorption onto natural bacterial consortia: Testing universal adsorption behavior: Geochimica et Cosmochimica Acta, v. 68, p. 3231-3238.

DAvis, J.M., and VINEY, C., 1998, Water-mucin phases: Conditions for mucus liquid crystallinity: Thermochimica Acta, v. 315, p. 39-49.

Furukawa, Y., 2001, Biogeochemical consequences of infaunal activities. Macro and microorganisms in marine sediments coastal and estuarine studies: Geochemical Transactions, v. 2, doi: 10.1039/b108381c.

Furukawa, Y., 2005, Biogeochemical consequences of infaunal activities, in Kristensen E., Haese, R.R., and Kostka J.E., eds., Macro and Microorganisms in Marine Sediments: Coastal and Estuarine Studies, v. 60, p. 159-177.

Gingras, M.K., Pemberton, S.G., Muelenbachs, K., and Machel, H., 2004, Conceptual models for burrow-related, selective dolomitization with textural and isotopic evidence from the Tyndall Stone, Canada: Geobiology, v. 2, p. 2130 .

Gum, J.R., JR., Hicks, J.W., Toribara, N.W., Rothe, E.-M., Lagace, R.E., and Kim, Y.S., 1992, The Human Muc2 intestinal mucin has cysteine-rich subdomains located both upstream and downstream of its central repetitive region: Journal of Biological Chemistry, v. 267, p. 21375-21383.

Han, Y., and AizenberG, J., 2003, Effect of magnesium ions on oriented growth of calcite on carboxylic acid functionalized self-assembled monolayer: Journal of the American Chemical Society, v. 12, p. 4032-4033.

Har-El, R., and TAnzer, M.L., 1993, Extracellular matrix 3: Evolution of the extracellular matrix in invertebrates: FASEB Journal, v. 7, p. 1115-1123.

Herbelin, A.L., and Westall, J.C., 1999, FITEQL 4.0: A computer program for determination of chemical equilibrium constants from experimental data: Report 99-01, Department of Chemistry, Oregon State University, Corvallis, Oregon.

Hong, Z., Chasan, B., Bansil, R., Turner, B.F., and Bhaskar, K.R., 2005, Atomic force microscopy reveals aggregation of gastric mucin at low $\mathrm{pH}$ : Biomacromolecules, v. 6, p. 3458-3466.

Koretsky, C.M., Meile, C., and Van Cappellen, P.V., 2002, Quantifying bioirrigation using ecological parameters: A stochastic approach: Geochemical Transactions, v. 3, p. 17-30.

Kostka, J.E., Roychoudhury, A., and Van Cappellen, P., 2002, Rates and controls of anaerobic microbial respiration across spatial and temporal gradients in saltmarsh sediments: Biogeochemistry, v. 60, p. 49-76.

KRISTENSEN, E., 1984, Effect of natural concentrations on nutrient exchange between a polychaete burrow in estuarine sediment and the overlying water: Journal of Experimental Marine Biology and Ecology, v. 75, p. 171-190.

Kristensen, E., 2001, Impact of polychaetes (Nereis spp. and Arenicola marina) on carbon biogeochemistry in coastal marine sediment. A review: Geochemical Transactions, v. 2, p. 92-104.

Kristensen, E., Jensen, M.H., and Andersen, T.K., 1985, The impact of polychaete (Nereis virens Sars) burrows on nitrification and nitrate reduction in estuarine sediments: Journal of Experimental Marine Biology and Ecology, v. 85, p. 75-91.

Kristensen, E., and KostKa, J.E., 2005, Macrofaunal burrows and irrigation in marine sediment: Microbiological and biogeochemical interactions, in Kristensen, E., Kostka, J.E., and Haese, R., eds., Interactions Between Macro- and Microorganisms in Marine Sediments: American Geophysical Union, Washington, D.C., p. 125-157.

Lalonde, S.V., Dafoe, L., Pemberton, S.G., Gingras, M.K., and Konhauser, K.O., 2010, Investigating the geochemical impact of burrowing animals: Proton and cadmium adsorption onto the mucus lining of Terebellid polychaete worms: Chemical Geology, v. 271, p. 44-51.

Lang, T., Hansson, G.C., and Samuelsson, T., 2007, Gel-forming mucins appeared early in metazoan evolution: Proceedings of the Natural Academy of Sciences of the United States of America, v. 104, p. 16209-16214. 
Marriott, C., and Gregory, N.P., 1990, Mucus physiology and pathology, in Lanaerts, V., Gurny, R., eds., Bioadhesive Drug Delivery Systems: CRC Press, Boca Raton, Florida, p. 1-24

Mastrodonato, M., Gherardi, M., Todisco, G., Sciscioli, M., and Lepore, E., 2006, The epidermis of Timarete filigera (Polychaeta, Cirratulidae): Histochemical and ultrastructural analysis of the gland cells: Tissue and Cell, v. 38, p. 279-284.

MitTereR, R.M., 1971, Comparative amino acid composition of calcified and noncalcified polychaete worm tubes: Comparative Biochemistry and Physiology Part B: Comparative Biochemistry, v. 38, p. 405-409.

Over, D.J., 1988, Lingulid brachiopods and Lingulichnus from a Silurian shelf-slope carbonate sequence, Delorme Group, Mackenzie Mountains, Northwest Territories: Canadian Journal of Earth Sciences, v. 25, p. 465-471.

OvER, D.J., 1990, Trace metals in burrows walls and sediments, Georgia Bight, USA Ichnos, v. 1, p. 31-41

Pearson, N.J., and Gingras, M.K., 2006, An ichnological and sedimentological facies model for muddy point-bar deposits: Journal of Sedimentary Research, v. 76, p. 771-782.

Petersen, K., Kristensen, E., and Bjerregaard, P., 1998, Influence of bioturbating animals on flux of cadmium into estuarine sediment: Marine Environmental Research, v. 45, p. 403-415.

Seilacher, A., 2007, Trace Fossil Analysis: Springer, Berlin, 226 p.

Stabili, L., Schirosi, R., Licciano, M., and Giangrande, A., 2009, The mucus of Sabella spallanzanii (Annelida, Polychaeta): Its involvement in chemical defence and fertilization success: Journal of Experimental Marine Biology and Ecology, v. 374 , p. $144-149$

Storch, V., 1988, The Ultrastructure of Polychaeta Integument, in Westheide, W., Hermans, C.O., eds., Microfauna Marina: Gustav Fisher Verlag, Stuttgart, p. 1336.
Strous, G.J., and DekKer, J., 1992, Mucin-type glycoproteins: Critical Reviews in Biochemistry and Molecular Biology, v. 27, p. 57-92

TRUitT, R.E., and WebeR, J.H., 1981, Determination of complexing capacity of Fulvic acid for copper (II) and cadmium (II) by dialysis titration: Analytical Chemistry, v. 53 , p. $337-342$.

Wang, D., Wallace, A.F., De Yoreo, J.J., and Dove, P.M., 2009, Carboxylated molecules regulate magnesium content of amorphous calcium carbonates during calcification: Proceedings of the National Academy of Sciences of the United States of America, v. 106, p. 21511-21516.

WebB, A.P., and EyRE, B.D., 2004, The effect of natural populations of the burrowing and grazing soldier crab (Mictyris longicarpus) on sediment irrigation, benthic metabolism and nitrogen fluxes: Journal of Experimental Marine Biology and Ecology, v. 309, p. 1-19.

Ziebis, W., Forster, S., HuetTel, M., and Jørgensen, B.B., 1996, Complex burrows of the mud shrimp Callianassa truncata and their geochemical impact in the sea bed: Nature, v. 382, p. 619-622

ZeNGeR, D.H., 1996, Dolomitization of the "C" zone, Red River Formation (Upper Ordovician) in deep core, Williston Basin, Richland County, eastern Montana: Contributions to Geology, v. 31, p. 57-75.

Zhu, Q., Aller, R., and FAn, Y., 2006, Two-dimensional pH distributions and dynamics in bioturbated marine sediments: Geochimica et Cosmochimica Acta, v. 70 , p. $4933-4949$.

Zorn, M.E., Muehlenbachs, K., Gingras, M.K., Konhauser, K.O., Pemberton, S.G., and Evoy, R., 2007, Stable isotopic analysis reveals evidence for groundwater-sediment-animal interactions in a marginal-marine setting: PALAIOS, v. 22, p. 546-553.

ACCEPTED JUNE 1, 2011 